\title{
An unusual case of spontaneous unilateral ruptured twin ectopic pregnancy
}

\author{
Shakti Jain, Karishma Sharma, Shweta Singh \\ Corresponding author: Dr. Karishma Sharma, Junior Resident, Department of Obstetrics \& \\ Gynaecology, Motilal Nehru Medical College, Prayagraj, UP, India; Email : \\ drkarishmasharma@gmail.com
}

Distributed under Attribution-Non Commercial - Share Alike 4.0 International (CC BY-NC-SA 4.0)

\section{$\underline{\text { ABSTRACT }}$}

\begin{abstract}
Unilateral twin ectopic pregnancy is an extremely rare condition, occurring in 1/20.000-250.000 pregnancies with approximately only 100 cases reported till date in literature. This report illustrates a rare case of ruptured ectopic pregnancy which occurred due to unilateral twin ectopic pregnancy. A 35 years old woman $\mathrm{G}_{7} \mathrm{P}_{6}$ reported to emergency with amenorrhea of one and half months and pain in lower abdomen. Her urine pregnancy test was positive and ultrasonography showed multiple (twin) ectopic gestational sacs in left adnexa. Color doppler showed ring of fire sign encircling both the gestational sacs suggestive of twin ectopic pregnancy. Exploratory laparotomy with left salpingo-oophorectomy and histopathological examination of the specimens confirmed the diagnosis.
\end{abstract}

Keywords: Ectopic pregnancy, twin ectopic, ovarian ectopic.

Ectopic pregnancy is a major health risk for women of child bearing age and if not diagnosed and treated properly can lead to life threatening complications. Many factors increase the risk of ectopic pregnancy important being pelvic inflammatory disease, adhesions, ART, etc. Unilateral twin ectopic gestation is a rare condition, first described, in 1891 by De Ott ${ }^{1}$. The first unruptured twin tubal pregnancy was described in 1986 by Santos ${ }^{2}$. Unilateral twin ectopic pregnancy is rare occurring with a frequency of $1 / 20.000$ 125.000 pregnancy and $1 / 200$ ectopic pregnancy ${ }^{3-5}$. Moreover, ectopic pregnancy has a recurrence rate of $10 \%$ for one and $25 \%$ for two or more previous ectopic pregnancies ${ }^{6}$. Twin ectopic is a rare condition with only approximately 100 diagnosed cases worldwide. Here, we report a rare case of unilateral spontaneous twin ectopic pregnancy (left tubal and left ovarian) presenting with 6 weeks of gestation.

Case

A 35 years old woman, married since 8 years, gravida 7 , para 6 with 4 live issues, all by vaginal delivery, not using any contraceptive with a positive urine pregnancy test presented to our department of obstetrics and gynaecology, Swaroop Rani Nehru Hospital as an emergency patient with history of amenorrhea of one and half months and pain in lower abdomen since 6 to 7 days prior to admission. There was history of vaginal spotting 20 days back and her previous menstrual cycles were regular. There was no history suggestive of any major medical or surgical illness in past including tuberculosis. Personal and family history was not contributory.

On general examination, she had pallor and tachycardia with pulse rate of 110/minute regular and blood pressure 110/70 mm Hg. On per abdominal examination, there was no tenderness or palpable mass. Per speculum examination was normal. On per vaginal examination uterus was normal size, retroverted and right adnexa was clear, however, in left adnexa there was fullness and tenderness with tender cervical movements.

Her urine pregnancy test was positive and all her laboratory investigations were sent urgently. A transvaginal

Received: $1^{\text {st }}$ September 2020, Peer review completed: $4^{\text {th }}$ February 2021, Accepted: $30^{\text {th }}$ March 2021.

Jain S, Sharma K, Singh S. An unusual case of spontaneous unilateral ruptured twin ectopic pregnancy. The New Indian Journal of OBGYN. 2022; 8(2): xxxx. 
ultrasound scan (TVUS) was performed using a GE Healthcare (Milwaukee, WI, USA) scanner, equipped with a 5-9 $\mathrm{MHz}$ endocavity transducer. Realtime grey scale examination revealed normal sized uterus with thinned endometrium and clots in endometrial cavity. Hyperechoic lesions with peripheral vascularity measuring approximately $3.6 \times 3.5 \times 3 \mathrm{~cm}^{3}$ was seen towards the left cornua extending outwards towards the left adnexa. Left ovary showed some hemorrhagic fluid and right ovary was normal (figure 1). Mild fluid collection with dense internal echoes was noted in the pouch of Douglas. On color doppler there were well defined two extrauterine gestational sacs, one in the left cornua and other in the left ovary both showing ring of fire encircling the gestational sacs, thus confirming the diagnosis of multiple (twin) ectopic pregnancy on left side.

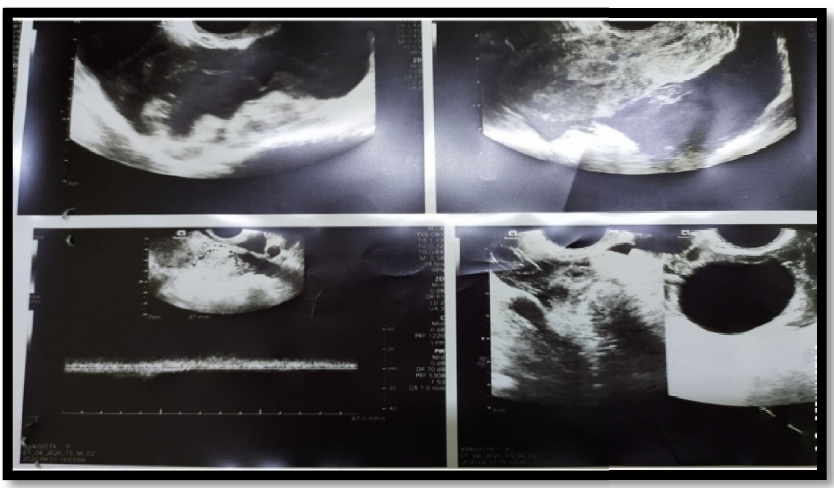

Figure 1: Sonography with color doppler imaging two distinct heterogenous mass like lesions with peripheral intense vascularity resembling "Rings of fire" suggesting the diagnosis of unilateral twin ectopic pregnancy.

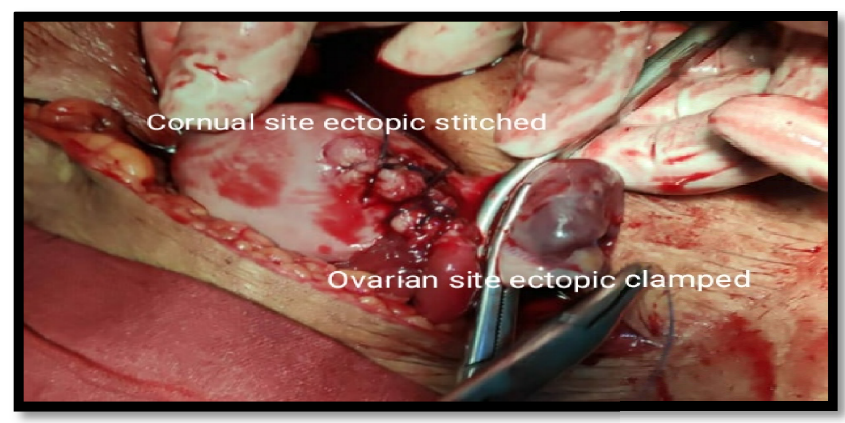

Figure 2: Intraoperative left cornual site ectopic removed and stitched and left ovarian site ectopic clamped showing unilateral twin ectopic gestation.

Her preoperative investigations were within normal limit, so she was subjected for emergency exploratory laparotomy. Intraoperatively, there was moderate hemoperitoneum and uterus was bulky. Left fallopian tube was ruptured at the cornual site and left ovary was also ruptured showing some hemorrhagic fluid and membrane like structure. Left sided salpingo-oophorectomy with bilateral round ligament plication was done (figure 2). Intraoperative blood transfusion was done. Specimens were sent for histopathological examination. The patient did well postoperatively and was discharged on 7 th postoperative day. The histopathological examination also confirmed the diagnosis of left sided tubal and left ovarian pregnancy.

\section{Discussion}

Incidence of ectopic pregnancy is increasing since 1970 and more incidence is seen in developing countries (2-6\%). Several factors are thought to increase the risk of ectopic pregnancy, pelvic inflammatory disease with maximum risk and others being advanced maternal age, adhesions, operative trauma, and in vitro fertilization. This case of ectopic pregnancy is particularly peculiar as it is a unilateral spontaneous twin ectopic pregnancy - similar cases are exceedingly rare, with very limited instances reported in medical literature worldwide thus far ${ }^{7}$.

Unilateral twin ectopic pregnancy is a rare condition with approximately only 100 cases reported till date. There are less than 10 unilateral ectopic twin pregnancies reported with cardiac activity in both embryos. In 1994, Gualandi et al reported the first case of unilateral tubal twin pregnancy with cardiac activity in both embryos by endovaginal USG ${ }^{8}$. In 2001, Goker et al reported a case of unilateral twin ectopic pregnancy following an IVF cycle ${ }^{9}$. In 2002, Hanchate et al reported a patient with a live twin ectopic pregnancy with no predisposing factors ${ }^{10}$.

Based on case reports from the literature, monozygotic and monoamniotic are the most frequent (95\%) among unilateral twin pregnancies, dizygotic being a rare instance. The delay in tubal transport may play a role in the extensiveness of unilateral twin ectopic implantation; conversely it has been also supposed that the larger size of the twin cell mass itself causes the transport retard. Some authors explain twin ectopic pregnancy as a mere result of a bilateral ovulation. Compared to a same sized singleton pregnancy, the chance of rupture for a twin ectopic one are lower as trophoblastic invasion may be less due to lower gestational age at presentation in the latter case ${ }^{11}$.

Serum $\beta \mathrm{hCG}$ can be much higher than the discriminatory zone of 1500-2000 $\mathrm{mIU} / \mathrm{ml}$ valid for singleton ectopic pregnancy (with a mean of 9846), due to the larger trophoblastic tissue ${ }^{12}$. Transvaginal USG is recommended for detailed evaluation with a sensitivity of $87.0-99.0 \%$, 
specificy of $94.0-99.9 \%$ and as resolution for uterine and adnexal structure is superior. The diagnostic markers are extrauterine gestational sacs, adnexal mass and ring of fire sign encircling the gestational sacs. Being somehow similar and somehow different, the management of twin ectopic pregnancy can't just mirror the singleton one.

Treatment depends on the clinical presentation, size, and complications and includes conservative, medical or surgical intervention.

\section{Conclusion}

When making a diagnosis of ectopic pregnancy, even though rare, the chance of early diagnosis of ectopic pregnancy is important due to the high mortality and morbidity risks associated with this condition. Urgency for early diagnosis and expedited treatment is even more pronounced in twin ectopic pregnancies. Twin implant has to be considered and must be looked for while doing USG scanning, especially in patients having IVF treatment and PID.

\section{Conflict of interest: None. Disclaimer: Nil.}

\section{References}

1. De Ott D. A case of unilateral tubal twin gestation. Annales de Gyn'ecologie et d'Obst'etrique. 1891; 36: 304.

2. Santos CA, Sicuranza BS, Chatterjee MS. Twin tubal gestation diagnosed before rupture. Perinatol Neonatol. 1986; 10: 52-3

3. Goswami D, Agrawal N, Arora V. Twin tubal pregnancy: A large unruptured ectopic pregnancy. J Obstet Gynaecol Res. 2015; 41(11): 1820-2

4. Tam T, Khazaei A. Spontaneous unilateral dizygotic twin tubal pregnancy. J Clin Ultrasound. 2009 Feb; 37: 2-104
5. Vohra S, Mahsood S, Shelton H, Zaedi K, Economides DL. Spontaneous live unilateral twin ectopic pregnancy - A case presentation. Ultrasound. 2014; 22(4): 243-6

6. Ghanbarzadeh N, Nadjafi-Semnani M, Nadjafi-Semnani A, Nadjfai-Semnani F, Shahabinejad S. Unilateral twin tubal ectopic pregnancy in a patient following tubal surgery. J Res Med Sci. 2015; 20(2):196-8

7. Alkatout I, Honemeyer U, Strauss A, et al. Clinical diagnosis and treatment of ectopic pregnancy. Obstet Gynecol Surv. 2013; 68: 571-81.

8. Gualandi M, Steemers N, de Keyser JL. First reported case of preoperative ultrasonic diagnosis and laparoscopic treatment of unilateral, twin tubal pregnancy. Rev Fr Gynecol Obstet. 1994; 89: 134-36.

9. Göker EN, Tavmergen E, Ozçakir HT, Levi R, Adakan S. Unilateral ectopic twin pregnancy following an IVF cycle. J Obstet Gynaecol Res. 2001; 27: 213-15.

10. Hanchate V, Garg A, Sheth R, Rao J, Jadhav PJ, Karayil D. Transvaginal sonographic diagnosis of live monochorionic twin ectopic pregnancy. $\mathrm{J}$ Clin Ultrasound. 2002; 30: 52-56

11. Hois EL, Hibbeln JF, Sclamberg JS. Spontaneous twin tubal ectopic gestation. J Clin Ultrasound. 2006; 34(7): 352-5

12. Eddib A, Olawaiye A, Withiam-Leitch M, Rodgers B, Yeh J. Live twin tubal ectopic pregnancy. Int J Gynaecol Obstet. 2006; 93(2):154 -5.

\footnotetext{
Shakti Jain ${ }^{1}$, Karishma Sharma ${ }^{2}$, Shweta Singh ${ }^{3}$

${ }^{1}$ Assistant Professor, Department of Obstetrics \& Gynaecology, Motilal Nehru Medical College, Prayagraj, UP, India; ${ }^{2}$ Junior Resident, Department of Obstetrics \& Gynaecology, Motilal Nehru Medical College, Prayagraj, UP, India; ${ }^{3}$ Junior Resident, Department of Obstetrics \& Gynaecology, Motilal Nehru Medical College, Prayagraj, UP, India.
} 